\title{
Correlations between the detection of e antigen or antibody and electron microscopic pattern of hepatitis B surface antigen (HBsAg) associated particles in the serum of HBsAg carriers
}

\author{
C. TREPO ${ }^{1}$, R. G. BIRD ${ }^{2}$, AND A. J. ZUCKERMAN 2 \\ From the Lindsley F. Kimball Research Institute of the New York Blood Center, \\ 310 East 67th Street, New York, New York 10021 and the London School of Hygiene and Tropical \\ Medicine, Keppel Street (Gower Street), London WC1E 7HT, England ${ }^{2}$
}

SUMmARY The distribution of HBsAg associated particles, especially the presence of Dane particles, $\vec{z}$ was studied by electron microscopy in coded sera of 68 chronic HBsAg carriers. Results were

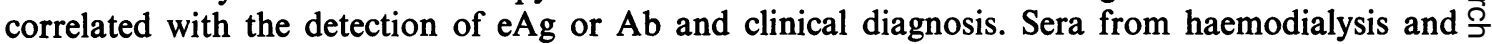
chronic hepatitis patients showed a high prevalence of e antigenaemia $(9 / 13,69 \cdot 2 \%$ and $8 / 19,42 \cdot 1 \%) \vec{\omega}$ and Dane particles (11 and 16 respectively, $84 \%$ ). By contrast, out of 36 chronic asymptomatic $\checkmark$ carriers of $\mathrm{HBsAg}, 28(77.7 \%)$ were positive for e antibody but only $1(2.7 \%) \mathrm{had}$ eAg. Dane particles were found in $13 / 36(36 \cdot 1 \%)$. A statistically significant correlation was observed between the detection of eAg and the presence of Dane particles $(94.4 \%)$ in the serum. However, Dane particles $\frac{\partial}{0}$ were still observed in 10/28 (35.7\%) of anti-e positive sera. The data suggest that eAg may be linked to complete $\mathrm{HB}$ virions.

Previous reports have shown that e antigen $(\mathrm{eAg})$ is frequently detected in the serum of hepatitis $B$ surface antigen (HBsAg) carriers with chronic active hepatitis or undergoing haemodialysis whereas anti-e is associated with the healthy carrier state (Magnius and Espmark, 1972; Eleftheriou et al., 1975; El Sheikh et al., 1975; Feinman et al., 1975; Trepo et al., 1976). Other data also indicate that eAg may be associated with infectivity (Magnius and Espmark, 1972; Magnius et al., 1975; Okada et al., 1976; Skinhøj et al., 1976), detection of hepatitis B core antigen in liver nuclei (Trepo et al., 1976; Murphy et al., 1976), higher titre of $\mathrm{HBsAg}$ (Trepo et al., 1976), and a greater proportion of Dane particles in the serum (Nielsen et al., 1974; El Sheikh et al., 1975).

Although many reports have been devoted to the study of $\mathrm{HBsAg}$ associated particles by electron microscopy (EM) in acute or chronic hepatitis or in silent HBsAg carriers (Nielsen et al., 1973; Stannard et al., 1973), there have been very few 1Present address: Pavillon H, Hopital Edouard-Herriot, 69374 Lyon Cedex 2, France

Received for publication 14 July 1976 systematic studies comparing the changes in patterns of particle distribution in various conditions (Almeida, 1972; Couleru et al., 1973; Yamada,용 1974; Zuckerman, 1975). None of these was per-: formed under code.

To investigate further the clinical significance of $\delta$ the $\mathrm{eAg} / \mathrm{Ab}$ system and its relationship with $\mathrm{HBsAg}$ associated particles we examined by electron 0 microscopy coded sera from 68 chronic $\mathrm{HBsAg}$ carriers and correlated the results with detection o of $\mathrm{eAg}$ or $\mathrm{Ab}$ as well as the clinical status of the patients.

\section{Material and methods}

PATIENTS STUDiED

Sera were obtained from 68 subjects, all of whom had been found to be persistent HBsAg carriers for more than a year. Nineteen patients had chronic hepatitis, five with the persistent type and 14 with the active type as defined by an international committee ${ }_{0}^{-}$ (De Groote et al., 1968). Thirteen HBsAg patients were undergoing chronic haemodialysis for renal insufficiency and 36 were asymptomatic volunteer blood donors with repeatedly normal serum alanine 
aminotransferase detected as carriers (CAC) by routine $\mathrm{HBsAg}$ screening, performed by reverse passive haemagglutination (Prince et al., 1975). Evidence of liver disease was assessed by routine clinical and laboratory evaluation.

\section{SEROLOGICAL METHODS}

The available sera were initially retested for $\mathrm{HBsAg}$ by radioimmunoassay (RIA) (Ausria II, Abbott Laboratories). The specificity of all positive results for HBsAg was established by repeating the RIA test after neutralisation with known human antiHBs positive sera (Prince et al., 1973).

$\mathrm{eAg}$ and anti-e were tested in parallel by counterelectrophoresis and immunodiffusion as described by Magnius and Espmark (1972). Counterelectrophoresis was carried out using the same agarose medium as for immunodiffusion with veronal buffer pH 8.6 and a constant current of $10 \mathrm{~mA}$ for 45 minutes. Plates were read after 24 hours' incubation at $28^{\circ} \mathrm{C}$ in a humid chamber.

The specificity of samples positive for eAg was confirmed by immunodiffusion after five-fold concentration of the serum.

A coded serum specimen from each of the 68 HBsAg carriers was sent frozen to the London School of Hygiene and Tropical Medicine for EM studies. Specimens were processed and examined after negative staining by methods which have been described elsewhere (Zuckerman, 1970, 1975).

\section{Results}

SEROLOGY FOR EAg AND ANTI-e

Results of eAg and anti-e testing among the various groups of HBsAg carriers are summarised in Table 1. The highest proportion of eAg positivity was found among haemodialysis (69.2\%) and chronic hepatitis $(42.1 \%)$ patients, whereas only one out of 36 asymptomatic blood donors $(2.7 \%)$ was found positive for eAg; in contrast, anti-e was detected in $28 / 36(77.7 \%)$ of these but in none of the chronichepatitis or haemodialysis patients.

\section{ELECTRON MICROSCOPY}

Examination by EM of samples from $68 \mathrm{HBsAg}$ carriers revealed particles characteristic of $\mathrm{HBsAg}$ in 53 (Table 2). In the 15 others, very few particles could be seen on first testing and identification was difficult. These samples were therefore retested by immune electron microscopy after incubation with anti-HBs. Eleven of these were definitely found to contain aggregated HBsAg particles and four contained particles of all sizes not identified by EM as hepatitis B antigen.

Six patterns of particle distribution were observed (Table 3):

1 scattered $22 \mathrm{~nm}$ particles and filaments

2 scattered particles including $43 \mathrm{~nm}$ Dane particles

3 aggregated particles without Dane particles

4 aggregated particles with Dane particles

$5 \mathrm{HBsAg}$ particles demonstrable by immune EM only

6 particles which could not be definitely identified as HBsAg

A good correlation was found between the distribution of particles and the clinical diagnosis: scarce $22 \mathrm{~nm}$ particles without Dane particles and filaments requiring the use of immune EM for their identification were observed among $13 / 36(36 \cdot 1 \%)$ $\mathrm{CAC}$ and restricted to them with the exception of one haemodialysis and one chronic hepatitis case. By contrast, Dane particles were also found in $13 / 36$ CAC $(36.1 \%)$, in $11 / 13(84.6 \%)$ of haemodialysis, and $16 / 19(84.2 \%)$ of chronic hepatitis patients.

COMPARISON BETWEEN EAg/Ab DETECTION, EM FINDINGS, AND CLINICAL STATUS

As shown in Table 4, a strong correlation was found between detection of $\mathrm{eAg}$ and the presence of Dane particles in the serum. Dane particles were indeed found in $17 / 18(94.4 \%)$ of eAg positive sera, in $13 / 22(59.1 \%)$ of sera without eAg or $\mathrm{Ab}$, and in $10 / 28(35.7 \%)$ of those with anti-e.

With the exception of one haemodialysis case, all cases positive for eAg had easily detectable Dane particles by EM. However, Dane particles were detected in many more instances than was $\mathbf{e A g}$ (Tables 1, 3, and 5). Out of $68 \mathrm{HBsAg}$ carriers, $40(58.8 \%)$ had Dane particles in the serum compared with $18(26.4 \%)$ who were found positive for

Table 1 Detection of $\mathrm{eAg}$ and anti-e by immunodiffusion and counterelectrophoresis in 68 chronic HBs Ag carriers according to their clinical status

\begin{tabular}{|c|c|c|c|c|}
\hline Diagnosis & Number of cases & eAg positive (\%) & anti-e positive $(\%)$ & Neither eAg nor anti-e positive (\%) \\
\hline Chronic hepatitis & 19 & $\begin{array}{c}8 \\
(42 \cdot 1)\end{array}$ & 0 & $\begin{array}{l}11 \\
(57 \cdot 2)\end{array}$ \\
\hline Haemodialysis & 13 & $\begin{array}{c}9 \\
(69 \cdot 2)\end{array}$ & $\mathbf{0}$ & $\begin{array}{c}4 \\
(30.7)\end{array}$ \\
\hline Asymptomatic blood donors & 36 & $\begin{array}{c}1 \\
(2 \cdot 7)\end{array}$ & $\begin{array}{l}28 \\
(77 \cdot 7)\end{array}$ & $\begin{array}{c}7 \\
(19 \cdot 4)\end{array}$ \\
\hline
\end{tabular}


Table 2 Electron microscopic findings in various groups of HBs Ag carriers

\begin{tabular}{|c|c|c|c|}
\hline \multirow[t]{2}{*}{ Electron microscopic findings } & \multicolumn{3}{|c|}{ Diagnosis (no. studied) } \\
\hline & Haemodialysis (13) & Chronic hepatitis (19) & $\begin{array}{l}\text { Asymptomatic blood donors } \\
\text { (36) }\end{array}$ \\
\hline Scattered $22 \mathrm{~nm}$ and filaments & 1 & 2 & 8 \\
\hline Scattered $22 \mathrm{~nm}$ and filaments and Dane particles & 7 & $1 \overline{5}$ & 11 \\
\hline Aggregated $22 \mathrm{~nm}$ and filaments & 0 & $\mathbf{0}$ & 2 \\
\hline $\begin{array}{l}\text { Aggregated } 22 \mathrm{~nm} \text { and filaments and Dane } \\
\text { particles }\end{array}$ & 4 & 1 & 2 \\
\hline Particles identified only by immune EM & 0 & 0 & 11 \\
\hline Failure to identify $\mathrm{HBsAg}$ & 1 & 1 & 2 \\
\hline
\end{tabular}

Table 3 Detection of particles in various groups of HBsAg carriers

\begin{tabular}{|c|c|c|c|c|}
\hline \multirow[t]{2}{*}{ Diagnosis } & \multirow[t]{2}{*}{ Number } & \multicolumn{3}{|c|}{ Number (and percent) of subjects with } \\
\hline & & Dane particles & No Dane particles & Few particles \\
\hline Haemodialysis & 13 & $\begin{array}{l}11 \\
(84 \cdot 6)\end{array}$ & $\begin{array}{c}2 \\
(15 \cdot 3)\end{array}$ & $\begin{array}{c}1 \\
(7 \cdot 6)\end{array}$ \\
\hline Chronic hepatitis & 19 & $\begin{array}{c}16 \\
(84 \cdot 2)\end{array}$ & $\begin{array}{c}3 \\
(45 \cdot 7)\end{array}$ & $\frac{1}{(5 \cdot 2)}$ \\
\hline Asymptomatic blood donors & 36 & $\begin{array}{l}13 \\
(36 \cdot 1)\end{array}$ & $\begin{array}{c}23 \\
(63 \cdot 8)\end{array}$ & $\begin{array}{l}13 \\
(36 \cdot 1)\end{array}$ \\
\hline
\end{tabular}

Table 4 Correlation between eAg and anti-e and detection of Dane particles in HBsAg carriers

\begin{tabular}{lll}
\hline Serological findings & Proportion with Dane particles detected (\%) \\
\hline eAg & $17 / 18$ & $(94.4)^{1}$ \\
Neither eAg nor anti-e & $13 / 22$ & $(59.1) \quad$ P $<0.05 ~ N S$ \\
Anti-e & $10 / 28$ & $(35.7)^{1}$ \\
\hline${ }^{1} \mathrm{P}<0.001$ &
\end{tabular}

eAg. Among the $13 \mathrm{HBsAg}$ carriers negative for both $\mathrm{eAg}$ and $\mathrm{Ab}$ who had Dane particles, there were $2 / 13(15.3 \%)$ haemodialysis, $8 / 19$ (42.1\%) chronic hepatitis, and $3 / 7(42 \cdot 8 \%)$ CAC.

No significant difference in clumping of Dane particles or other particles was observed, either between the different clinical categories of carriers or between those with e or anti-e.

\section{Discussion}

The distribution of HBsAg particles, especially the frequency of Dane particles, has been found to be similar in chronic hepatitis and haemodialysis patients but is quite different in CAC (Nordenfelt and Kjellen, 1975). Striking differences in the infectivity of these various types of carriers has been observed (Magnius and Espmark, 1972; Heathcote et al., 1974) and the remarkable abundance of Dane particles in haemodialysis and chronic hepatitis is well documented (Almeida, 1972; Couleru et al., 1973; Yamada, 1974). However, the frequency of detection of Dane particles in CAC remains controversial. Although absent for some authors, in the serum of CAC with normal liver function tests and histology (Nielsen et al., 1973), Dane particles were still detectable in $28 / 34$ cases of another long-term prospective follow-up study (Holtermüller et al., 1975). Dane particles were detected in $36.1 \%$ of CAC in this series, a proportion also reported previously (Stannard et al., 1973). Since our results were obtained by EM and not by immune electron microscopy, this is an underestimate of the real frequency of Dane particles in CAC. In this study, the prevalence of $\mathrm{eAg}$ in chronic hepatitis and haemodialysis patients and of $\mathrm{eAb}$ among asymptomatic blood donors is similar to that reported by Magnius et al. (1975). HBsAg particle patterns differed dramatically between $\mathrm{eAg}$ and $\mathrm{eAb}$ positive chronic $\mathrm{HBsAg}$ carriers. Comparison of $\mathrm{eAg} / \mathrm{Ab}$ detection with $\mathrm{EM}$ findings indicates a possible link between eAg and Dane particles. Like others, we observed a statistically 0 significant correlation between the detection of $N$ eAg and the presence of Dane particles. Neurath et al. (1976) have presented evidence that eAg may be an additional antigen present on the surface of Dane particles and large filaments but absent from the $22 \mathrm{~nm}$ particles. As the Dane particles may be the circulating form of heaptitis B virus, this finding could explain the correlations between $\mathrm{AAg}$, presence of Dane particles in the serum, and the apparent greater infectivity of $\mathrm{HBsAg}$ carriers with $\mathrm{eAg}$ and/or Dane particles (McAuliffe et al., 1976; Neurath et al., 1976). 
The prevalence of Dane particles in anti-e positive sera is still controversial. Nielsen et al. (1974) failed to detect any Dane particles in those sera but El Sheikh et al. (1975) observed a small proportion of Dane particles by immune EM in sera from five out of 27 patients with e antibody, nine of whom had chronic hepatitis. Dane particles were detected in this EM study in 10/28 anti-e positive sera from CAC with repeatedly normal serum alanine aminotransferase values and liver function tests. Agglutinated particles were seen in only two cases. These latter findings do not seem to support the suggestion that eAg could be another surface Ag of the Dane particle. Although it may be speculated that production of anti-e in large excess (Yamada, 1974) and/or of low avidity could preclude aggregation of Dane particles, these discrepancies may more likely reflect differences in antigenic specificity of the e complex (McAuliffe et al., 1976). The existence of defective Dane particles representing a deletion mutant of hepatitis B virus (Gerin et al., 1975) which may lack eAg could be an alternative hypothesis. The detection of Dane particles in a significant proportion of anti-e sera helps to explain why some anti-e HBsAg positive sera may still retain infectivity (Berquist et al., 1976).

The greater proportion of sera with fewer particles among anti-e positive CAC may be explained by the significantly lower HBsAg serum titres observed in such carriers (Trepo et al., 1976).

The quantitative and qualitative correlations found between $\mathrm{HBsAg}$ associated particles, eAg or $\mathrm{Ab}$ detection, and the clinical status of the carriers are puzzling and call for a specific link of eAg to the complete hepatitis B viron itself. Further studies are needed to clarify the exact relations of the e antigens and antibodies to the morphological forms of HBsAg and clinical or immune status of the host. In the present state of knowledge, the EM may still provide clinically valuable additional information on the potential evolution and contagiousness of hepatitis B infections.

The work at the London School of Hygiene and Tropical Medicine is supported by generous grants from the Medical Research Council, the World Health Organisation, the Wellcome Trust, the Department of Health and Social Security, and the Wolfson Foundation.

\section{References}

Almeida, J. D. (1972). Individual morphological variations seen in Australia antigen positive sera. Amer. $J$. Dis. Child., 123, 303-309.

Berquist, K. R., Maynard, J. E., and Murphy, B. L.
(1976). Infectivity of serum containing $\mathrm{HBsAg}$ and antibody to e antigen (Letter). Lancet, 1, 1026-1026.

Couleru, O., Moulias, R., Peter, F., Bousquet, O., German, A., and Loeper, J. (1973). Etude ultrastructurale de l'antigèneà "Australie". Nouv. Presse Méd., 2, 1633-1644.

De Groote, J., Desmet, V. J., Gedigk, P., Korb, G., Popper, H., Poulsen, H., Scheuer, P., Schmid, M., Thaler, H., Vehlinger, E., and Wepler, W. (1968). A classification of chronic hepatitis. Lancet, 2, 626-628.

El Sheikh, N., Woolf, I. L., Galbraith, R. M., Eddleston, A. L. W. F., Dymock, I. W., and Williams, R. (1975). e Antigen-antibody system as indicator of liver damage in patients with hepatitis-B antigen. Brit. med. J., 4, 252-253.

Eleftheriou, N., Thomas, H. C., Heathcote, J., and Sherlock, S. (1975). Incidence and clinical significance of $e$ antigen and antibody in acute and chronic liver disease. Lancet, 2, 1171-1173.

Feinman, S. V., Berris, B., Sinclair, J. C., Wrobel, D. M., Murphy, B. L., and Maynard, J. E. (1975). e Antigen and anti-e in HBsAg carriers. Lancet, 2, 1173-1174.

Gerin, J. L., Ford, E. C., and Purcell, R. H. (1975). Biochemical characterization of Australia antigen: evidence for defective particles of hepatitis B virus. Amer. J. Path., 81, 651-661.

Heathcote, J., Gateau, P., and Sherlock, S. (1974). Role of hepatitis-B antigen carriers in non-parenteral transmission of the hepatitis-B virus. Lancet, 2, 370-372.

Holtermüller, K. H., Baumeister, H. G., Schäfer, A., Eckardt, V., Arndt-hanser, A., Ewe, K., Wandel, E., Baas, U., and Overby, L. R. (1975). Prospective study of hepatitis $B$ antigen ( $\mathrm{HBsAg}$ ) positive carriers. (Abstract). Gastroenterology, 69, 830.

McAuliffe, V. J., Purcell, R. H., and Le Bouvier, G. L. (1976). e:a third hepatitis B antigen? New Engl. J. Med., 294, 779-781.

Magnius, L. O. and Espmark, J. A. (1972). New specificities in Australia antigen positive sera distinct from the Le Bouvier determinants. J. Immunol., 109, 1017 1021.

Magnius, L. O., Lindholm, A., Lundin, P., and Iwarson, S. (1975). A new antigen-antibody system: clinical significance in long-term carriers of hepatitis B surface antigen. J. Amer. med. Ass., 231, 356-359.

Murphy, B. L., Peterson, J. M., Smith, J. L., Gitnick, G. L., Auslander, M. O., Berquist, K. R., Maynard, J. E., and Purcell, R. H. (1976). Correlation between fluorescent antibody detection of hepatitis $B$ core antigen in liver biopsies and the presence of $\mathrm{e}$ antigen in serum. Infect. Immun., 13, 296-297.

Neurath, A. R., Trepo, C., Chen, M., and Prince, A. M. (1976). Identification of additional antigenic sites on Dane particles and the tubular forms of hepatitis B surface antigen. J. gen. Virol., 30, 277-285.

Nielsen, J. O., Dietrichson, O., and Juhl, E. (1974). Incidence and meaning of the "e" determinant among hepatitis-B-antigen positive patients with acute and chronic liver diseases. Lancet, 2, 913-915.

Nielsen, J. O., Nielsen, M. H., and Elling, P. (1973). Differential distribution of Australia-antigen-associated 
particles in patients with liver diseases and normal carriers. New Engl. J. Med., 288, 484-487.

Nordenfelt, E. and Kjellen, L. (1975). Dane particles, DNA polymerase, and e-antigen in two different categories of hepatitis B antigen carriers. Intervirology, 5, 225-232.

Okada, K., Kamiyama, I., Inomata, M., Imai, M., Miyakawa, Y., and Mayumi, M. (1976). e Antigen and anti-e in the serum of asymptomatic carrier mothers as indicators of positive and negative transmission of hepatitis B virus to their infants. New Engl. J. Med., 294, 746-749.

Prince, A. M., Brotman, B., Jass, D., and Ikram, H. (1973). Specificity of the direct solid-phase radioimmunoassay for detection of hepatitis-B antigen. Lancet, 1, 1346-1350.

Prince, A. M., Ikram, H., Chicot, D., Wright, R., Vnek, J., Neurath, R., Lippin A., and Swiss, S. (1975). A new reversed passive haemagglutination test for detection of HBsAg. Vox Sang. (Basel), 29, 319-329.

Skinhøj, P., Cohn, J., and Bradburne, A. F. (1976).
Transmission of hepatitis type B from healthy HBsAg- 음 positive mothers. Brit. med. J., 1, 10-11.

Stannard, L. M., Moodie, J., Keen, G. A., and Kipps, A. (1973). Electron microscopic study of the distribution $\overline{0}$ of the Australia antigen in individual sera of 50 serologically positive blood donors and two patients with serum hepatitis. J. clin. Path., 26, 209-216.

Trepo, C. G., Magnius, L. O., Schaefer, R. A., and Prince, $\varrho$ A. M. (1976). Detection of e antigen and antibody: correlations with hepatitis $B$ surface and hepatitis $B \overrightarrow{0}$ core antigens, liver disease, and outcome in hepatitis $\mathrm{N}$ infections. Gastroenterology, 71, 804-808.

Yamada, G. (1974). Electron microscopic observations on $\stackrel{\omega}{\omega}$ hepatitis B antigen-associated particles in the sera of patients with various liver diseases. Acta Med. Okayama, 28, 27-45.

Zuckerman, A. J. (1970). Electron microscopy and $\dot{\omega}$ immune electron microscopy. Bull. Wld Hlth Org., 42, $\frac{\mathrm{N}}{\sigma}$ 975-977.

Zuckerman, A. J. (1975). The ultrastructure of hepatitis antigens. In his Human Viral Hepatitis, 2nd edition, pp. 123-141. North Holland, Amsterdam. 